\title{
Segregation analysis in families with Charcot-Marie-Tooth disease allows reclassification of putative disease causing mutations
}

Rune Østern ${ }^{1,2^{*}}$, Toril Fagerheim ${ }^{1}$, Helene Hjellnes ${ }^{1}$, Bjørn Nygård ${ }^{1}$, Svein Ivar Mellgren ${ }^{2,3}$ and Øivind Nilssen ${ }^{1,2}$

\begin{abstract}
Background: The identification of disease causing, or putative disease causing, mutations in index patients with Charcot-Marie-Tooth disease (CMT) allows for genetic testing of family members. Relevant variants identified in index patients are of either definite, likely or uncertain pathogenicity. The main objective of this study was to make an evaluation of the family investigations performed as part of the assessment of genetic variants of unknown clinical significance (VUS).
\end{abstract}

Methods: Between 2004 and 2010 molecular genetic family investigations were requested for 87 family members from 41 families harbouring PMP22dup or genetic variants in GJB1, MPZ, MFN2 and NEFL. Relatives were tested for the family mutation and data from the requisitions were evaluated by means of statistical tools.

Results: The results within each indication category are presented and discussed in detail. Twenty-two relatives ( 9 affected) from eight families were included in the segregation analyses, which invoked reclassification of three MFN2 mutations, two of which were de novo substitutions (c.2146_2148dup, c.692C > T). One MFN2 substitution was downgraded due to non-segregation (c.1709 A > G), and a MPZ substitution (c.103 G>A) upgraded due to segregation with the phenotype in the family.

Conclusions: The results allow for the evaluation of the patient phenotypes ascertained in families, as opposed to the phenotypic descriptions of index patients. They indicate that de novo MFN2 mutations are regularly found in patients with a classical CMT2 phenotype. They also demonstrate the importance of a precise clinical and neurophysiologic diagnosis of affected family members. This particularly applies for the examination of variants of uncertain clinical significance. Finally, the fact that $14,6 \%$ of affected relatives tested for (probable or certain) pathogenic mutations were mutation negative, demonstrates that clinical evaluation alone is not always sufficient in order to determine their diagnosis. We believe that the results will aid in the estimation and planning of resources required for the various aspects of family evaluations in CMT.

Keywords: Charcot-Marie-Tooth, Genetic and inherited disorders, Neuromuscular diseases, Mutation analysis, Family investigations

\footnotetext{
* Correspondence: runeostern@online.no

1 Department of Medical Genetics, University Hospital of North-Norway, N09038 Tromsø, Norway

${ }^{2}$ Department of Clinical Medicine, Neuromuscular Research Group, University

of Tromsø, N09037 Tromsø, Norway

Full list of author information is available at the end of the article
}

\section{Biomed Central}

(c) 2014 Østern et al.; licensee BioMed Central Ltd. This is an Open Access article distributed under the terms of the Creative Commons Attribution License (http://creativecommons.org/licenses/by/2.0), which permits unrestricted use, distribution, and reproduction in any medium, provided the original work is properly cited. The Creative Commons Public Domain Dedication waiver (http://creativecommons.org/publicdomain/zero/1.0/) applies to the data made available in this article, unless otherwise stated. 


\section{Background}

Charcot Marie Tooth disease (CMT) is an inherited peripheral neuropathy and the prevalence of the phenotype has been determined to be 1:2500 in Western Norway and 1 per 1214 in South-eastern Norway (Akershus County) $[1,2]$. Symptoms of the classical phenotype encompass distal limb weakness and muscular atrophy, tendon areflexia, and sensory loss, most noticeable in the legs. Foot deformities like pes cavus and hammertoes are often found [3]. The first symptoms usually occur in the first or second decade and the physical impairments are mostly mild, and with slow progression [4]. The nerve conduction velocity in the median motor nerve (MNCV) is measured to differentiate between the autosomal dominant demyelinating type 1 and the autosomal dominant axonal type $2(\mathrm{CMT} 1<38 \mathrm{~m} / \mathrm{s}<$ CMT2). Intermediate forms of CMT are characterized by relatives with MNCVs in both ranges due to both demyelinating and axonal pathology [5]. Autosomal recessive forms (CMT4), and X-linked forms (CMTX) are designated by the inheritance pattern, independent of NCS results. Within each CMT category subclasses are determined by the disease associated gene or locus, and more than 40 CMT associated genes and loci have been identified [6].

More than $90 \%$ of the mutations detected in a diagnostic setting are constituted by a PMP22dup, or a sequence variant in the $M P Z$ or the MFN2 gene, causing autosomal dominant CMT, or a mutation in the GJB1 gene, causing X-linked CMT [7-9]. Patients with a duplication of the $P M P 22$ region develop a classical CMT phenotype in most cases, but the phenotype is also characterized by inequality in severity, even between close relatives [10]. The median MNCV is always $<38 \mathrm{~m} / \mathrm{s}$ [10-13]. Patients with $M P Z$ mutations may have a grave demyelinating phenotype, Dejerine-Sottas syndrome/CMT3 (DSS, MIM 145900) or congenital hypomyelinating neuropathy (MIM 605253) with very slow MNCVs or they may have a milder CMT1 or CMT2 phenotype with MNCVs in the intermediate or axonal range [14]. MFN2 mutations may be coupled with the classical CMT2 phenotype, but individuals who experience an early disease onset ( $<10$ years) also tend to have severe symptoms, sometimes also optic atrophy $[15,16]$. Males with a GJB1 mutation typically have a more severe phenotype than females, and mostly demonstrate MNCVs in the demyelinating or intermediate range, whereas females commonly are asymptomatic or mildly affected, with MNCVs in the intermediate or axonal range [17].

Relatives of index patients with a documented sequence variant may request genetic counselling and testing. The requests for testing of family members fall within four categories: diagnostic, prenatal, and presymptomatic testing of family members for certain or likely pathogenic variants, and finally, carrier testing/segregation analysis of relatives for the investigation of genetic variants of unknown clinical significance. This study is founded upon a previous report on diagnostic testing, the index patients of this study are described in detail there [9]. The main objective of this study was to make a further assessment of the family investigations performed as part of the evaluation of genetic variants of unknown clinical significance (VUS). We included 87 family members of 41 index patients. Here we provide an overview of the indications for testing, the distribution of relatives under each category as well as the test outcome. We believe that these results will aid in estimating and planning the extent of resources required for the various aspects of family evaluations in CMT performed by diagnostic laboratories. Finally, the results presented show that clinical evaluation alone is not always sufficient in order to determine the diagnosis of affected family members.

\section{Methods}

\section{Patient population}

Between 2004 and 2010, 435 index patients underwent diagnostic testing for CMT and 72 genetic variants of either definite, likely or uncertain pathogenicity were identified [9]. Subsequent molecular genetic family investigations were requested for 31 families (43\%) harbouring PMP22dup (6) or mutations in GJB1 (12), MPZ (7), MFN2 (5) and NEFL (1) (Table 1). All mutations were suspected to invoke autosomal dominant or X-linked (GJB1) inheritance. For completeness, four individual samples received in 2002 and 2003 were included because their extended families were investigated during the years 2004-2010. In addition, we received samples from 12 relatives of 10 index cases with PMP22 duplications (9), and a GJB1 mutation causing p.Arg183Cys, diagnosed in other laboratories. In total, requests for testing of 87 family members from 41 families were received (Figure $1 \mathrm{~A}$ and $\mathrm{B}$ ). In 4 cases testing was rejected.

Table 1 The 31 index patients diagnosed at our laboratory

\begin{tabular}{cccc}
\hline Classification $^{\boldsymbol{t}}$ & Gene & N indexes & N total \\
\hline 5 & GJB1 & 10 & 18 \\
& PMP22dup & 6 & \\
MPZ & 2 & 5 \\
4 & GJB1 & 2 & \\
MPZ & 2 & 8 \\
MFN2 & 1 & \\
& MPZ & 3 & \\
& NEFL & 1 & \\
& MFN2 & 4 &
\end{tabular}

${ }^{\dagger}$ Classification of genetic variants in accordance with the recommendations from the IARC Unclassified Genetic Variants Working Group; $5=$ definitely pathogenic, $4=$ likely pathogenic, $3=$ uncertain, $2=$ likely not pathogenic, $1=$ definitely not pathogenic [18]. 


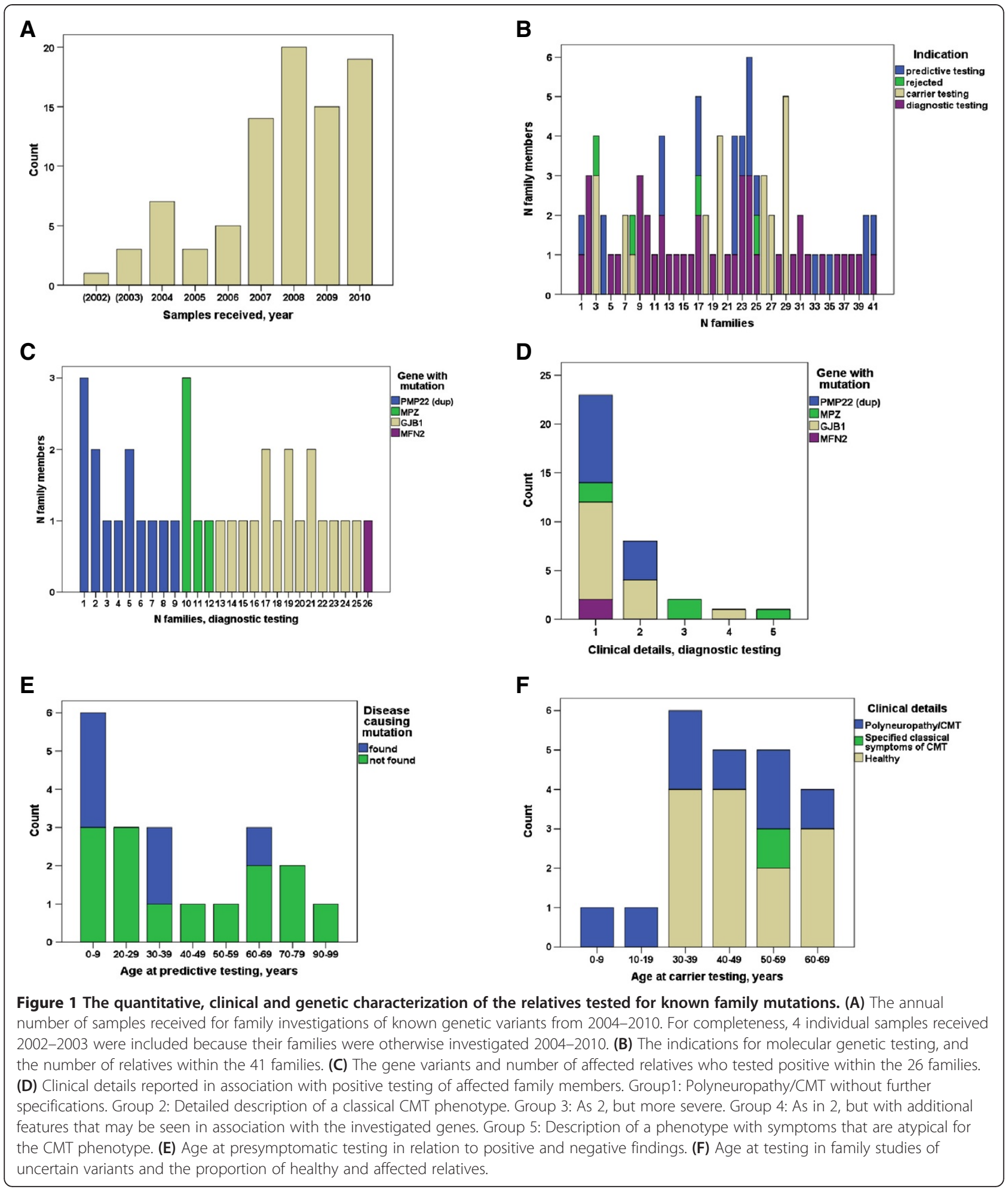

\section{Genetic analyses}

A Genovision M48 (Qiagen) or Biorobot EZ-1 (Qiagen) system was used to extract DNA from peripheral blood cells. Relatives were tested for the specific mutation previously identified in the index patient. Quantitative alterations of the PMP22 region were assessed by amplification (SALSA MLPA KIT P033-B2 CMT1, MRC Holland, Amsterdam). The Applied Biosystems 3130xl Genetic Analyzer performed the fragment analysis of PCR products. DNA sequencing of the MPZ, GJB1, 
MFN2 and NEFL coding exons including flanking intron sequences were performed as described in Østern et al., 2013 [9].

\section{Data collection, statistics and endpoint measures}

The data sampled from the requisitions and analyzed with the Statistical Package for the Social Sciences (SPSS) version 20.0 included: the sample year and test indication (diagnostic, presymptomatic, carrier, prenatal), clinical details and results on NCS, the age at onset and age at testing, the number of genetically verified affected relatives, the gender of the index patient as well as their relatives, whether or not the mutation was found, and if yes, the name of the gene/mutation and the interpretation of its consequences. The NCS results were classified as demyelinating, axonal, or mixed demyelinating and axonal. The clinical details were divided into: 1: Requests for CMT testing without relevant complementary clinical details, 2: Clinical details supportive of a classical CMT phenotype, 3: As in 2, but significantly more severe, 4: As in 2, but with supplemental traits known to be associated with the genes under investigation (such as tremor, sensorineural hearing impairment), 5: A polyneuropathy phenotype that is atypical for hereditary sensorimotor neuropathy (e.g. HSN-like, HMN-like, prominent upper limb symptoms). (Further details have been published previously [9]). The Alamut software (Interactive Biosoftware, San Diego, CA, USA) and literature studies were used to judge the clinical relevance of the genetic variants. The variants were classified in compliance with the proposal from The IARC Unclassified Genetic Variants Working Group; $5=$ definitely pathogenic, $4=$ likely pathogenic, 3 = uncertain, 2 = likely not pathogenic, 1 = definitely not pathogenic [18]. Class 3-5 variants were defined as positive findings in this study, whereas class 1-2 variants were defined as negative findings.

With the exception of diagnostic testing, genetic investigations were performed after genetic counselling. Follow up studies of class 3 variants were performed with standard methods, including carrier testing of family members, paternity testing and investigation of control samples [19]. The reclassification of a sequence variant was defined as the adjustment of the interpretation from class 3, to class 2 or 4 after extended investigations. Diagnostic, prenatal, and presymptomatic testing was offered for genetic variants of definite or likely clinical relevance (class 4 and 5).

The study was approved by the Norwegian Data Inspectorate and the Regional Committee for Medical Research Ethics who specified that it was not necessary with informed consent given by subjects/next-of-kin for this study. Procedures were in accordance with the revised Helsinki Declaration of 2008.

\section{Results}

The average number of family members for whom genetic tests were requested was 2.1 per index case (range 1-6). When the laboratory identified a PMP22 dup- in an index patient, it subsequently received samples of relatives for testing in $23 \%$ of the cases. The corresponding percentages for cases harbouring sequence variants in GJB1, MPZ and MFN2 were 60\%, 64\% and 42\%, respectively. The indications for molecular genetic testing in the various families and individual family members are illustrated in Figure 1B. In total, 41 positive molecular genetic findings were made $(67.2 \%)$ in 61 relatives tested for likely or certain pathogenic variants. Furthermore, in three family members and in three index patients from three families, class 3 mutations were upgraded to class 4 .

\section{Diagnostic testing of affected family members for definite} or likely pathogenic genetic variants (class 5 and class 4 )

Diagnostic testing was performed in 41 affected relatives from 29 families with class 5 or class 4 mutations. Six affected relatives (14.6\%), three from families with PMP22 duplications, one harbouring an $M P Z$ mutation and two with GJB1 mutations, tested negative. NCS results were reported as normal in two and were unspecified in four. For all six, "polyneuropathy" or "CMT" was the only clinical information reported. Age at onset was specified in three cases (5-10, 30-40, 40-50 years), and age at testing was $8,15,36,38,46$ and 54 years respectively.

Thirty-five affected relatives, from 26 families, tested positive for class 4/5 mutations identified in the corresponding index patent (Figure 1C). Average age at testing was 27.6 years (range 2 months -78 years). NCS results were reported only in $28.6 \%$ of the affected relatives.

Only scarce clinical information was given for $65.7 \%$ of the affected relatives; such as "polyneuropathy" or "CMT" (clinical group 1) (Figure 1D). The remaining majority (22.9\%) had specified a classical CMT phenotype (clinical group 2). In a family with an $M P Z$ mutation two patients were classified as severe (clinical group 3) and one as atypical (clinical group 5). This family harboured a c.368C > A (p.Gly123Val) substitution in the MPZ gene. The index mother and two of her sons had Dejerine-Sottas syndrome, and a daughter was admitted to the intensive care unit with hypotonia and respiratory difficulties at the age of two months. Another exception was a 42 year old female with CMT and a c.490C > T (p.Arg164Trp) mutation in the GJB1 gene who had tremor from early childhood, particularly of the head, muscular cramps and fasciculation's (clinical group 4). The MFN2 sequence variant, c.653 T > C (p.Leu218Pro), was identified in a mother and her 16 year old son with CMT2 [9]. They had an extensive family history of polyneuropathy; however, other family members were not available for testing. The $\mathrm{p}$. Leu218Pro residue is situated in the important GTPase 
domain of the protein and is conserved down to c.elegans and was interpreted as a class 4 variant based on in silico analyses.

\section{Presymptomatic testing of healthy family members for definite or likely pathogenic genetic variants (class 5 and class 4)}

Presymptomatic testing was performed in 20 healthy relatives from 12 families with class 5 or class 4 mutations. Average age at testing was 37.0 years (range 2 - 92 years, Figure 1E). In six minors, aged 15 or younger, for whom NCS data were not available, one PMP22dup and two GJB1 mutations were detected. In 14 relatives, aged 16 years or older, two with normal NCS results and 12 for whom NCS results were lacking, one PMP22dup and two GJB1 mutations were detected.

Relatives included in the control group for the assessment of genetic variants of unknown clinical significance documented in the index patient (class 3)

In order to evaluate genetic variants of unknown significance carrier testing and segregation analyses were carried out in 22 relatives from eight families. Of nine clinically affected relatives NCS results were available for three (Figure 1F). Average age at testing was 44.7 years (range $3-66$ years). The patients were older than 30 years with the exception of two cases, a three year old affected girl was tested for a c.410G > A (p.Gly137Asp) mutation in the MPZ gene, and a 12 year old affected girl was tested for a c.2146_2148 dup (p.Ala716dup) mutation in the MFN2 gene. Eight class 3 sequence variants, and their secondary classification after family studies, are listed in Table 2. After segregation studies the classification of mutation pathogenicity was upgraded from class 3 to class 4 for two independent MFN2 mutations as they showed to have occurred de novo in one isolated case of CMT2 and in a patient with an affected carrier child. One MFN2 mutation was downgraded from class 3 to class 2 since it was also detected in two healthy family members aged 36 and 65 years. Finally, one $M P Z$ mutation could be upgraded from class 3 to class 4 after the detection of the same mutation in an affected person remotely related to an index patient.

Altogether three cases of de novo MFN2 mutations were identified [9]. The first index patient, harbouring a de novo c.2146_2148dup (p.Ala716dup) mutation, had normal motor development up to the age of eight years. The patient then had a slowly progressing polyneuropathy with development of pes cavus and hammertoes. At the age of 35 the patient had bilateral drop foot, and was still fully employed. The child of the patient was investigated clinically at the age of three due to parental concerns, but was without muscular weakness at the time of assessment. However, NCS and EMG performed six months later were compatible with axonal polyneuropathy. The second patient with a de novo c.692C > T (p.Ser231Phe) substitution in the MFN2 gene had a clinical development similar to that of the index patient with the c.2146_2148dup mutation. The third de novo mutation, a c.250A > G (p.Lys84Glu) substitution in the MFN2 gene, was identified in a 12 year old child with severe mixed (axonal and demyelinating) polyneuropathy, scoliosis, contractures, respiratory difficulties and encephalopathy. None of the patients had optic atrophy.

Table 2 Class 3 sequence variants not reported in the HGMDp database or other sources at the time of identification, and secondary classification after family studies

\begin{tabular}{|c|c|c|c|c|c|c|c|c|c|c|}
\hline \multirow[t]{2}{*}{ Gene } & \multirow[t]{2}{*}{ Family } & \multicolumn{2}{|c|}{ Mutation } & \multirow{2}{*}{$\begin{array}{l}\mathrm{N} \text { tested } \\
\text { total }\end{array}$} & \multicolumn{2}{|c|}{$\mathrm{N}$ affected tested ${ }^{\dagger}$} & \multicolumn{2}{|c|}{$\mathrm{N}$ healthy tested ${ }^{\dagger}$} & \multirow{2}{*}{$\begin{array}{c}\text { Primary } \\
\text { classifi-cation }\end{array}$} & \multirow{2}{*}{$\begin{array}{c}\text { Secondary } \\
\text { classifi-cation }^{ \pm}\end{array}$} \\
\hline & & cDNA & Protein & & Pos & Neg & Pos & $\mathrm{Neg}$ & & \\
\hline \multirow[t]{4}{*}{ MFN2 } & $1^{*}$ & c. $250 A>G$ & p.Lys84Glu & 2 & 0 & 0 & 0 & $2^{\ddagger}$ & 3 & 3 \\
\hline & 2 & c.1709 A > G & p.Asn570ser & 4 & 1 & 0 & 2 & 1 & 3 & $2^{9}$ \\
\hline & $3^{*}$ & c.2146_2148 dup & p.Ala716dup & 3 & 1 & 0 & 0 & $2^{\ddagger}$ & 3 & 4 \\
\hline & $4^{*}$ & c. $692 C>T$ & p.Ser231Phe & 2 & 0 & 0 & 0 & $2^{\ddagger}$ & 3 & 4 \\
\hline \multirow[t]{3}{*}{$M P Z$} & $1^{*}$ & $c .410 \mathrm{G}>\mathrm{A}$ & p.Gly137Asp & 3 & 3 & 0 & 0 & 0 & 3 & 3 \\
\hline & 2 & c. $103 \mathrm{G}>\mathrm{A}$ & p.Asp35Asn & 3 & $2^{€}$ & 0 & 0 & 1 & 3 & 4 \\
\hline & $3^{*}$ & c.368 G>T & p.Gly123Val & 5 & 2 & 0 & 0 & 3 & 3 & 3 \\
\hline NEFL & $1^{*}$ & c.1027_1029del & p.Asp343del & 1 & 1 & 0 & 0 & 0 & 3 & 3 \\
\hline
\end{tabular}

${ }^{\dagger}$ In addition to index.

\$Primary classification of genetic variants in the index patient in accordance with the recommendations from the IARC Unclassified Genetic Variants Working Group; 4 = likely disease causing, $3=$ uncertain, 2 = likely not disease causing [18].

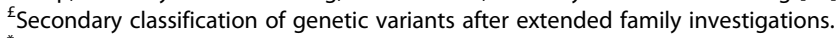

* Sequence variants reported in a previous work [9].

'Parents negative, de novo mutation in the first following generation. MFN2 family 1; ongoing investigation, MFN2 family 3 and 4; mutation not found in 200

control chromosomes. Paternity was genetically verified.

"This variant was later reported with a possible association to dHMN in a single Norwegian patient [24].

${ }^{\epsilon}$ One affected carrier remotely related to an index patient identified in 2012; not included in the total material. 


\section{Prenatal testing}

Nine female carriers at fertile age (21-42 years) were carriers of class 5 variants. Prenatal testing was requested in one case.

\section{Discussion}

In our experience clinicians and diagnostic laboratories have a low threshold for requesting/carrying out diagnostic testing of relatives with polyneuropathy. Accordingly, mutations were not identified in all affected family members $(85.4 \%)$. This may in part relate to the fact that NCS results were available only for a minority (28.6\%). One might anticipate a wider phenotypic spectrum among affected relatives as compared to index patients. However, this was not the case in the material presented here. Additional tremor and fasciculation's, as reported in a patient with a GJB1 mutation, or hypotonia and possibly a severe phenotype, as reported in an infant from a DSS family with a MPZ mutation, is within the known range of phenotypes. For the remaining affected relatives symptoms of classical CMT were reported. Mild symptoms were reported in two out of three cases with de novo mutation in MFN2, and age at onset $<10$ years of age, whereas the third patient had a phenotype more in accordance with the early onset group, as it is described elsewhere $[15,16,20]$. Thus, the phenotypes described in this cohort of affected relatives rather show a tendency towards the mild end of the spectrum, particularly in those carrying MFN2 mutations.

Presymptomatic testing of adult family members gave a detection rate (21\%) well below 50\%. This might be explained by the high mean age at testing (37.0 years), cases of de novo mutations and the inclusion of second degree relatives (3). De novo mutations in GJB1 are assumed to be rare [21]. Minors constituted 30\% (6/20) of the presymptomatic group in this material. Five patients had an affected parent, one an affected half sibling. Three of these patients showed a positive genetic test result.

Family investigations and segregation analyses are performed when genetic variants of uncertain clinical relevance (class 3 ) are revealed and in some cases, interpretations can be modified into class $1 / 2$ or class $4 / 5$, permitting more accurate advice in genetic counselling. Although the families described here are small, they sometimes have the power to weaken the suspicion of pathogenicity. The reclassification of variants identified in nuclear families is mostly achieved in isolated cases through the documentation of a de novo mutation in a known CMT associated gene [19]. In four of the eight families with class 3 variants interpretations were adjusted, three of them to class 4 , of which two harbored de novo mutations in the MFN2 gene (Table 2). Numerous de novo MFN2 mutations have been reported in several cohorts with severe symptoms, and some MFN2 mutations, for example c. $280 \mathrm{C}>\mathrm{T}$, have also been reported as de novo multiple times [15,16,22,23]. Our results therefore add to the data indicating that de novo MFN2 mutations are regularly found even in patients with a classical CMT2 phenotype [24].

When selecting healthy relatives for segregation analysis older individuals are preferred. The mean age at testing was higher in this group (44.7 years), as compared to the presymptomatic (37.0 years) and diagnostic (28.4 years) groups. An earlier CMT report indicated that many patients, and family members at risk, are uneducated about the possibility of genetic counselling and genetic testing [25]. We do not know to which extent this applies for the cohort presented here, but we do see that significantly more relatives are tested pr. index patient in the group included for segregation analysis (2.7), as compared to the presymptomatic (1.7) and diagnostic (1.4) groups. This probably reflects the more active role of the laboratory in the recruitment of relatives for the investigation of class 3 variants.

Prenatal diagnosis is available in most cases with known class 5 or class 4 variants. In this series only $1 / 9$ women in fertile age requested prenatal testing. Previously we have reported 72 index patients with CMT associated mutations, including 15 females with class 4/5 variants between the age of 20 and 46 years, of whom none asked for prenatal testing at pregnancy [9]. Thus, in our experience, Norwegian female carriers of CMT associated mutations rarely make use of prenatal diagnostics.

\section{Conclusion}

The results presented here clearly demonstrate that the precise diagnosis of affected family members should rely on the combination of NCS and genetic test results, not clinical assessment alone. This particularly applies for the investigation of the clinical significance of class 3 variants. They are coupled with uncertainties that often prevail in spite of meticulous family investigations. The implementation of next generation sequencing technologies in the diagnostic testing of index patients leads to an increase in the already large proportion of class 3 variants. Hence, there is a need for genetic counselling capacity and expertise to be scaled up accordingly to maintain a proportionate relationship between the capacity for diagnostic testing of index patients and the subsequent investigations of their families.

\footnotetext{
Competing interests

The authors declare that they have no competing interests.
}

\section{Authors' contributions}

$R \varnothing$ has taken part in all stages of the project including design and

conceptualization of the study, analysis and interpretation of the data and also in drafting and revising of the manuscript for intellectual content. TF has taken part in analysis and interpretation of the data and also in revising of 
the manuscript for intellectual content. $\mathrm{HH}$ has taken part in analysis and interpretation of the data and in revising of the manuscript for intellectual content. BN has taken part in analysis and interpretation of the data and in revising of the manuscript for intellectual content. SIM has taken part in all stages of the project including design and conceptualization of the study, analysis and interpretation of the data and also in drafting and revising of the manuscript for intellectual content. $\varnothing \mathrm{N}$ has taken part in all stages of the project including design and conceptualization of the study, analysis and interpretation of the data and also in drafting and revising of the manuscript for intellectual content. All authors read and approved the final manuscript.

\section{Acknowledgement}

This work was supported by The Norwegian Research Council Grant \# 199372.

\section{Author details}

'Department of Medical Genetics, University Hospital of North-Norway, NO9038 Tromsø, Norway. ${ }^{2}$ Department of Clinical Medicine, Neuromuscular Research Group, University of Tromsø, N09037 Tromsø, Norway.

${ }^{3}$ Department of Neurology, University Hospital of North-Norway, NO9038 Tromsø, Norway.

Received: 30 October 2013 Accepted: 6 January 2014

Published: 21 January 2014

\section{References}

1. Skre H: Genetic and clinical aspects of Charcot-Marie-Tooth's disease. Clin Genet 1974, 6:98-118.

2. Braathen GJ: Genetic epidemiology of Charcot-Marie-Tooth disease. Acta Neurol Scand 2012, 126(193):iv-22.

3. Harding AE, Thomas PK: The clinical features of hereditary motor and sensory neuropathy types I and II. Brain 1980, 103:259-280.

4. Carter GT, Abresch RT, Fowler WM Jr, Johnson ER, Kilmer DD, McDonald CM: Profiles of neuromuscular diseases. Hereditary motor and sensory neuropathy, types I and II. Am J Phys Med Rehabil 1995, 74(Suppl 5):140-149.

5. Nicholson G, Myers S: Intermediate forms of Charcot-Marie-Tooth neuropathy: a review. Neuromolecular Med 2006, 8:123-130.

6. Bird TD: Charcot-Marie-Tooth hereditary neuropathy overview. Gene Reviews 2013. [http://www.ncbi.nlm.nih.gov/books/NBK1358/] (accessed May 08, 2013).

7. Saporta AS, Sottile SL, Miller LJ, Feely SM, Siskind CE, Shy ME: Charcot-Marie-Tooth disease subtypes and genetic testing strategies. Ann Neurol 2011, 69:22-33.

8. Murphy SM, Laura M, Fawcett K, Pandraud A, Liu YT, Davidson GL, Rossor AM, Polke JM, Castleman V, Manji H, Lunn MP, Bull K, Ramdharry G, Davis M, Blake JC, Houlden H, Reilly MM: Charcot-Marie-Tooth disease: frequency of genetic subtypes and guidelines for genetic testing. J Neurol Neurosurg Psychiatry 2012, 83:706-710.

9. Østern R, Fagerheim T, Hjellnes H, Nygård B, Mellgren SI, Nilssen Ø: Diagnostic laboratory testing for Charcot Marie Tooth disease (CMT): the spectrum of gene defects in Norwegian patients with CMT and its implications for future genetic test strategies. BMC Med Genet 2013, 14:94.

10. Birouk N, Gouider R, Le Guern E, Gugenheim M, Tardieu S, Maisonobe T, Le Forestier N, Agid Y, Brice A, Bouche P: Charcot-Marie-Tooth disease type $1 \mathrm{~A}$ with 17p11.2 duplication. Clinical and electrophysiological phenotype study and factors influencing disease severity in 119 cases. Brain 1997, 120:813-823.

11. Bienfait HM, Verhamme C, van Schaik IN, Koelman JH, de Visser BW, de Haan RJ, Baas F, van Engelen BG, de Visser M: Comparison of CMT1A and CMT2: similarities and differences. J Neurol 2006, 253:1572-1580.

12. Marques W Jr, Freitas MR, Nascimento OJ, Oliveira AB, Calia L, Melo A, Lucena R, Rocha V, Barreira AA: 17p duplicated Charcot-Marie-Tooth 1A: characteristics of a new population. J Neurol 2005, 252:972-979.

13. Kim YH, Chung HK, Park KD, Choi KG, Kim SM, Sunwoo IN, Choi YC, Lim JG, Lee KW, Kim KK, Lee DK, Joo IS, Kwon KH, Gwon SB, Park JH, Kim DS, Kim SH, Kim WK, Suh BC, Kim SB, Kim NH, Sohn EH, Kim OJ, Kim HS, Cho JH, Kang SY, Park Cl, Oh J, Shin JH, Chung KW, et al: Comparison between clinical disabilities and electrophysiological values in Charcot-Marie-Tooth 1A patients with PMP22 duplication. J Clin Neurol 2012, 8:139-145.
14. Shy ME, Jáni A, Krajewski K, Grandis M, Lewis RA, Li J, Shy RR, Balsamo J, Lilien J, Garbern JY, Kamholz J: Phenotypic clustering in MPZ mutations. Brain 2004, 127:371-384.

15. Verhoeven K, Claeys KG, Züchner S, Schröder JM, Weis J, Ceuterick C Jordanova A, Nelis E, De Vriendt E, Van Hul M, Seeman P, Mazanec R, Saifi GM, Szigeti K, Mancias P, Butler IJ, Kochanski A, Ryniewicz B, De Bleecker J, Van den Bergh P, Verellen C, Van Coster R, Goemans N, Auer-Grumbach M, Robberecht W, Milic Rasic V, Nevo Y, Tournev I, Guergueltcheva V, Roelens F, et al: MFN2 mutation distribution and genotype/phenotype correlation in Charcot-Marie-Tooth type 2. Brain 2006, 129:2093-2102.

16. Chung KW, Kim SB, Park KD, Choi KG, Lee JH, Eun HW, Suh JS, Hwang JH, Kim WK, Seo BC, Kim SH, Son IH, Kim SM, Sunwoo IN, Choi BO: Early onset severe and late-onset mild Charcot-Marie-Tooth disease with mitofusin 2 (MFN2) mutations. Brain 2006, 129:2103-2118.

17. Dubourg O, Tardieu S, Birouk N, Gouider R, Léger JM, Maisonobe T, Brice A Bouche P, LeGuern E: Clinical, electrophysiological and molecular genetic characteristics of 93 patients with X-linked Charcot-Marie-Tooth disease. Brain 2001, 124:1958-1967.

18. Plon SE, Eccles DM, Easton D, Foulkes WD, Genuardi M, Greenblatt MS, Hogervorst FB, Hoogerbrugge N, Spurdle AB, Tavtigian SV: IARC unclassified genetic variants working group: sequence variant classification and reporting: recommendations for improving the interpretation of cancer susceptibility genetic test results. Hum Mutat 2008, 29:1282-1291.

19. Richards CS, Bale S, Bellissimo DB, Das S, Grody WW, Hegde MR, Lyon E, Ward BE: Molecular subcommittee of the ACMG laboratory quality assurance committee. ACMG recommendations for standards for interpretation and reporting of sequence variations: revisions 2007. Genet Med 2008, 10:294-300,

20. Chung KW, Suh BC, Cho SY, Choi SK, Kang SH, Yoo JH, Hwang JY, Choi BO: Early-onset Charcot-Marie-Tooth patients with mitofusin 2 mutations and brain involvement. J Neurol Neurosurg Psychiatry 2010, 81:1203-1206.

21. Meggouh F, Benomar A, Rouger H, Tardieu S, Birouk N, Tassin J, Barhoumi C, Yahyaoui M, Chkili T, Brice A, LeGuern E: The first de novo mutation of the connexin 32 gene associated with X linked Charcot-Marie-Tooth disease. J Med Genet 1998, 35:251-252.

22. Züchner S, Mersiyanova IV, Muglia M, Bissar-Tadmouri N, Rochelle J, Dadali EL, Zappia M, Nelis E, Patitucci A, Senderek J, Parman Y, Evgrafov O, Jonghe PD, Takahashi Y, Tsuji S, Pericak-Vance MA, Quattrone A, Battaloglu E, Polyakov AV, Timmerman V, Schröder JM, Vance JM: Mutations in the mitochondrial GTPase mitofusin 2 cause Charcot-Marie-Tooth neuropathy type 2A. Nat Genet 2004, 36:449-451.

23. Cho HJ, Sung DH, Kim BJ, Ki CS: Mitochondrial GTPase mitofusin 2 mutations in Korean patients with Charcot-Marie-Tooth neuropathy type 2. Clin Genet 2007, 71:267-272.

24. Braathen GJ, Sand JC, Lobato A, Høyer H, Russell MB: MFN2 point mutations occur in 3.4\% of Charcot-Marie-Tooth families. An investigation of 232 Norwegian CMT families. BMC Med Genet 2010, 29:11-48.

25. Arnold A, McEntagart M, Younger DS: Psychosocial issues that face patients with Charcot-Marie-Tooth disease: the role of genetic counseling. J Genet Couns 2005, 14:307-318.

\section{doi:10.1186/1471-2350-15-12}

Cite this article as: Østern et al:: Segregation analysis in families with Charcot-Marie-Tooth disease allows reclassification of putative disease causing mutations. BMC Medical Genetics 2014 15:12. 